\title{
The role of professionals in promoting independent living: Perspectives of self-advocates and front-line managers
}

\author{
Maria Pallisera $^{1}$ (D) | Montserrat Vilà ${ }^{1}$ | Judit Fullana ${ }^{1}$ (D) | Gemma Díaz-Garolera ${ }^{1}$ (D) | \\ Carolina Puyalto ${ }^{1}$ (D) | Maria-Josep Valls ${ }^{2}$
}

${ }^{1}$ Institute of Educational Research, University of Girona, Girona, Spain

${ }^{2}$ University of Lleida, Lleida, Spain

\section{Correspondence}

Maria Pallisera, Institute of Educational Research, University of Girona, Girona, Spain.

Email: maria.pallisera@udg.edu

Funding information

This work was supported by MINECO (Spanish Public Science Foundation) under Grant EDU2014-55460-R. The funding body has not imposed any restrictions on free access to or publication of the research data.
Background: Support from professionals plays an important role in helping people with intellectual disabilities to live an independent life. This research aims to analyse the role played by support professionals based on the perceptions of the professionals and self-advocates with intellectual disabilities. The research was conducted in Catalonia (Spain).

Method: A total of 33 interviews were conducted with front-line managers and 10 focus groups with 72 self-advocates. These were recorded and transcribed, and then analysed using thematic content analysis.

Results: Self-advocates particularly value professionals' interpersonal skills and emotional support. Front-line managers and self-advocates highlight training actions aimed at enhancing autonomy in the home and propose fostering natural supports and increasing the involvement of people with disabilities.

Conclusions: Making progress in the rights of people with intellectual disabilities to an independent life requires requires transforming the support model, promoting decision making among people with intellectual disabilities, and strengthening interpersonal skills linked to emotional support in the training of professionals.

\section{KEYWORDS}

front-line managers, independent living, people with intellectual disabilities, role of professionals, self-advocates, support staff

\section{1 | INTRODUCTION}

The care provided for adults with intellectual disabilities has undergone substantial modification in recent years due to the rejection of institutional models of disability (Barnes \& Mercer, 2010) and a commitment to social inclusion (Mansell \& Beadle-Brown, 2010). The Convention on the Rights of Persons with Disabilities (United Nations, 2006) represented a significant step forward in promoting the view of people with intellectual disabilities as individuals who have the right to decide about their life and participate actively in society. Article 19 establishes the right of all people with disabilities to decide where they want to live and with whom, and access to support that allows them equal access to community resources. Currently, the general trend in most Western countries is a transition from the residential model to a model based on group homes and personalized living settings (Wahlström, Bergström, \& Marttila, 2014). Group homes consist of ordinary housing shared by $3-10$ people, with support staff available during their residency. In personalized living settings, people with intellectual disabilities rents or owns a property, lives alone or with a chosen companion, and receives personalized support (McConkey, Keogh, Bunting, García Iriarte, \& Watson, 2016). However, despite the recognition of the right to independent living, the implementation of policies that promote personal choice and personalized support is advancing very slowly (Garcia-Iriarte, McConkey, \& Gilligan, 2016).

Although support from professionals (whether support staff, direct care workers, front-line managers or house managers) is a crucial element in advancing the right to independent living for 
people with intellectual disabilities (Bowey, Mcglaughlin, \& Saul, 2005; Dodevska \& Vassos, 2013; Hatton, Wigham, \& Craig, 2009; McGlaughlin, Gorfin, \& Saul, 2004), little attention has been paid in research to the role of professionals in supporting independent living processes (García Iriarte, Stockdale, McConkey, \& Keogh, 2016; Hastings, 2010; McConkey \& Collins, 2010). In addition, most of the literature published on this topic has only focused on the views of the professionals themselves (Dodevska \& Vassos, 2013; Hatton et al., 2009). Examples of this are the studies by Clement and Bigby (2012) and McConkey and Collins (2010). The former investigated the competencies of front-line managers, while the latter analysed the contribution of support staff in facilitating social inclusion in three different services: supported living schemes, shared housing and day centres. In all three services, among their duties staff were found to prioritize tasks related to personal care, while awarding less value to those related to social inclusion.

The views of people with intellectual disabilities regarding which elements they value in their relations with support professionals have played a less relevant role in the research, although they are necessary because their opinions may differ from those expressed by the latter (Dodevska \& Vassos, 2013; Duggan \& Linehan, 2013). Furthermore, including their views in the study of issues that affect them can lead to them having greater control over their own lives (Björnsdóttir, Stefánsdóttir, \& Stefánsdóttir, 2015). Their views have been studied in research conducted by Björnsdóttir et al. (2015), in a study focused on exploring adult autonomy; by Clarkson, Murphy, Coldwell, and Dawson (2009) on users resident in forensic settings; and by Roeden, Maaskant, and Curfs (2011) in a study exploring what clients with intellectual disabilities feel contributes to a successful working relationshio with caregivers. Some research has addressed the perspectives of both people with intellectual disabilities and professionals, such as those carried out by Hatton et al. (2009) and Dodevska and Vassos (2013). In both of the latter, what users valued most was the quality of interactions and support, while professionals valued the exercising of specific knowledge and practical work skills. Recent research conducted in Ireland by García Iriarte, Stockdale et al. (2016) and based on interviews with people with intellectual disabilities and professionals who supported them in their transition from residential to community living spaces has provided rich data on the transformation of the role in providing support for people moving from congregated group homes and personalized living arrangements.

The above studies highlight professionals' perceptions regarding their change in function given the transformation from a clinical model based on rehabilitation to a social model focused on providing support for people to achieve social inclusion (García Iriarte, Stockdale et al. (2016)). On the other hand, views expressed by people with disabilities suggest that support professionals' interpersonal skills (e.g., ability to listen, keeping calm, honesty, willing to help, kindness, respectfulness) should be taken into account along with their professional skills and knowledge (Dodevska \& Vassos, 2013). Thus, having a complete vision of the professional role that leads to improvements in both the distribution of support services and the recruitment and training of professionals requires contrasting the voices of people with intellectual disabilities and care professionals.

This article presents the results of research designed to provide an analysis of the role played by professionals offering support for independent living to people with intellectual disabilities in Catalonia (Spain), taking into account the opinions of both the professionals themselves and people with intellectual disabilities. In addition, the methodology used may contribute to developing methodological solutions that help to effectively include the voices of people with disabilities in the analysis of support relationships, as called for by Hastings (2010).

\subsection{Research context}

In Spain, care for people with intellectual disabilities has been managed through Act 13/1982 on the Social Integration of people with disabilities, following a model that has combined residential care with community-based services, with the group home model dominating in the latter case. As a result of the UN Convention's ratification, Act 1/2013 on the Rights of Persons with Disabilities and their Social Inclusion was enacted. This law recognizes independent living as one of its principles, but reproduces the same support models as established by the previous law. The different Spanish regions have specific projects to support independent life in the person's own home, although these initiatives are still in the minority. In their report on the state of policies that support independent living for people with intellectual disabilities, Verdugo, Jenaro, and Campo (2009) point out that in Spain the emphasis has been clearly placed on residential rather community-based support. In the case of Catalonia (the Spanish region where the research was conducted), since 2002 the government has regulated and promoted a yearly-renewable programme that provides financial assistance to adult people with intellectual disabilities living in their own home alone or in groups of up to four people, to cover a maximum of $10 \mathrm{hr}$ of professional support per person per week. The current amount ( $€ 500$ per month) is applied for directly by the person with intellectual disabilities to the local authority and, if granted, it is managed by the organization that provides the support. Organizations that wish to offer this service must previously be accredited by the local authority. Currently, 1,200 people benefit from this service in Catalonia. This programme is still ongoing, and no recent studies have been conducted to analyse its impact on independent living for people with intellectual disabilities.

\section{2 | METHOD}

This study forms part of a broader research project aimed at determining the difficulties faced by people with intellectual disabilities in realizing their plans for independent living in Spain, identifying the types of support that help them in this regard and making proposals for improvement. Before starting the research, the researchers applied for and were granted ethical approval. The research was 
authorized by both the University and MINECO (the Spanish Public Science Foundation). The article focuses specifically on the role of the support professionals.

\section{1 | Participants}

Two groups of individuals were involved in the study. The first consisted of 33 professionals, selected from front-line managers at 23 services providing housing support to adults with intellectual disabilities in Catalonia. They all provide the personalized support service at home (representing $38 \%$ of all organizations that manage personalized support for people with intellectual disabilities in the study area), and 19 of them also manage group homes. Selection criteria for recruitment were having at least 5 years' experience in organizing housing services, experience offering personalized support and having some management responsibility. Given that it is the organizations that decide whether to offer personalized support at home or not, there may be a certain bias among the participating professionals. They are, in all cases, front-line managers working in organizations that have a clear motivation to help people with disabilities to live with maximum autonomy in ordinary environments. The group comprised 25 women and 8 men. Of these, $27.3 \%$ had between 5 and 10 years of experience, $27.3 \%$ between 10 and 15 years, $21.2 \%$ between 15 and 25 years and $24.2 \%$ over 25 years. They all had a higher education degree in the field of Education or Psychology.

The second group consisted of 72 adults with intellectual disabilities (38 men and 34 women) who were members of self-advocacy groups. The decision to contact self-advocacy groups was based on the fact that these groups were founded with the aim of discussing issues directly related to the rights of people with disabilities, leading us to believe they would make a meaningful contribution to the research. The 25 self-advocacy groups existing in Catalonia in 2015 were invited to participate in the research through their regional coordination body. A total of 10 self-advocacy groups agreed to participate, all of which had been in operation for more than a year. In Spain, self-advocacy groups have been promoted by the Ministry of Social Affairs since 1998 and have links to organizations that provide care for adults with disabilities, which provide the groups with a support professional. Members tend to be users of special work centres or supported employment services, which generally receive only intermittent or limited support. The participants in the 10 groups were in different housing situations (some were in group homes, others in personalized supported arrangements and others in the family home). They either worked in the regular job market (via supported employment) or in sheltered workshops. The discussion within each group provided knowledge and reflections based on the experiences of the participants and those of colleagues.

\section{2 | Instruments}

An individual semi-structured interview was developed to be administered to front-line managers and a focus group was designed for use with self-advocates. The interviews conducted in this study were aimed at obtaining the views of front-line managers on different issues related to processes leading to independent living (IL). The focus groups were organized with the aim of facilitating participants' interaction, discussion and a contrast of opinions, views and experiences. Several authors have focused on the potential of focus groups in fostering the participation and empowerment of people with disabilities in the research process (Barr, McConkey, \& McConaghie, 2003; Kaehne \& O'Connell, 2010). The following topics were addressed in both the interviews and focus groups: assessment of current options/resources to support IL; the role of professionals; the role of organizations; the role of families; the role of people with intellectual disabilities; the role of friends; the Convention on the Rights of Persons with Disabilities; and the dream: their vision of how IL should be. This article focuses specifically on the role of the support professionals. Appendix 1 presents the questions asked to the front-line managers and self-advocates in interviews and focus groups regarding the role of professionals in promoting independent living.

\section{3 | Procedure}

Three support services were initially contacted in the local area and the snowball method was used to identify front-line managers to be interviewed. Each participant was asked to recommend a professional or service that offers personalized support for independent living. A researcher contacted the professionals to present the research objective, check whether they complied with the recruitment criteria and request their participation in the study. This recruitment process led to interviews with 33 professionals working in 23 organizations in 11 different locations. Before starting the interview, each participant was verbally re-informed of the research objective and asked to sign an informed consent form. The interview process ended when no new professionals were being proposed. The interviews were audiotaped and had an average duration of $80 \mathrm{~min}$.

Self-advocacy groups were requested to participate via their regional coordinating body. Meetings were held in seven different locations on the date and at the time chosen by members of the group. Participants signed a consent form which acknowledged their right to anonymity and included their permission for the focus group to be recorded. Consent forms were written in accessible language. Following the guidelines proposed by Kaehne and O'Connell (2010) and Barr et al. (2003), various strategies were applied to facilitate the discussion: an accessible script and the presence of a researcher at the meetings who, together with the facilitator, provided support throughout the discussion. In five of the focus groups theself-advocates preferred their support professional to be present. In these cases, the professional was present at the meeting but did not guide the self-advocates' involvement. All meetings were videotaped and had an average duration of $1 \mathrm{hr}$ $45 \mathrm{~min}$. 
TAB LE 1 Main themes (and subthemes) in interviews with front-line managers and focus groups with self-advocates

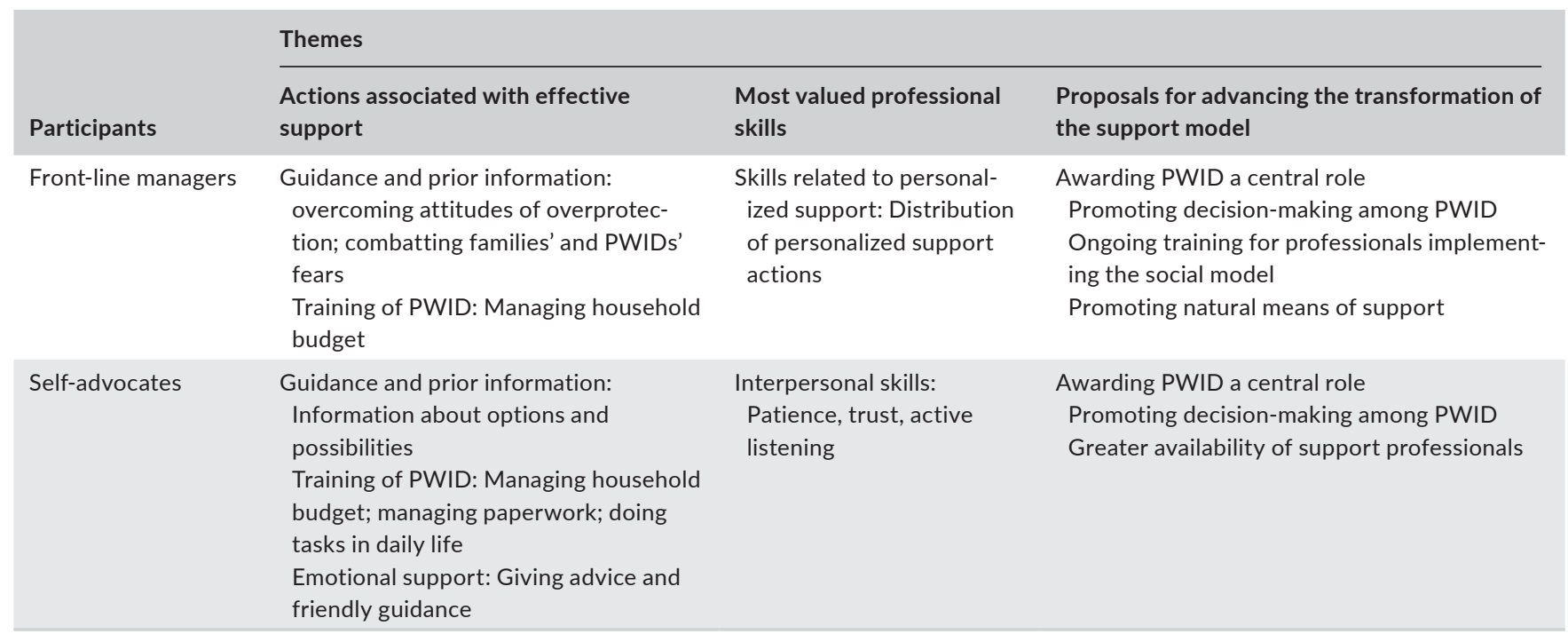

\section{4 | Data analysis}

The method used for analysis was thematic content analysis, a qualitative data analysis technique that allows patterns (themes) of a data set to be identified and analysed through a careful process of reading and re-reading the data (Fereday \& Muir-Cochrane, 2006). Based on Braun and Clarke's (2006) guidelines, the analysis was performed as follows: once the focus groups and interviews had been transcribed, three of the authors (the $2 \mathrm{nd}$, 3rd and 6th) carefully reviewed one-third of the interviews each, using the initial themes to manually encode the fragments they identified as being related to these themes and adding new codes. Two of the authors (the 1st and $2 \mathrm{nd}$ ) analysed the rest of the interviews from this initial list, and in turn established other new codes. Once all the interviews were encoded, a definitive list of codes was agreed upon and used to review the data corpus (interviews and FG). The fourth author collated each code together in separate computer files. Once the fragments had been classified into codes, the data were reviewed again, looking for relationships in order to establish organizing themes or patterns (Boyatzis, 1998). An initial map was then drawn up showing the relationships between these themes. After this, the data were reviewed again in order to identify sub-themes for each topic and the initial map was reformulated specifying the relationship between the themes and establishing their definition. Three of the authors (the 1st, 2nd and 4th) worked together on the review carried out in this phase. Table 1 shows the main themes (actions associated with effective support, most valued professional skills, and suggestions for transforming the support model), specifying the sub-themes that emerged for each group.

\section{3 | RESULTS}

The results of the research are presented below. First, we present the data corresponding to the views of the front-line managers, arranged according to the three main themes shown in Table 1. We then present the ideas expressed by the people with intellectual disabilities from the self-advocacy groups. ${ }^{1}$

\section{1 | Front-line managers}

With regard to actions associated with effective support, Guidance and prior information for people with intellectual disabilities (PWID) and their families was one of the support actions that the front-line managers deemed necessary to foster independent living processes for people with intellectual disabilities. They referred to the need to work with families to overcome attitudes of overprotection, as well as the fears felt by people with disabilities and their families. It must be ensured that the family is involved in and committed to the child's life path, and not enough prior joint work is generally done for the family to trust in the capabilities of the child. It is important to provide the family with information regarding possible means of support, services and pathways (employment, independent living, etc.), as well as opportunities for real life experiences:

\section{So when you start to think about life plans, or life goals, the person often says 'I want to live independently or I want to live alone...' and you can't talk to the family about this if you've not already addressed it with them... you have to start working with smaller and more specific things to in- volve the family, and then slowly move towards what the person really wants in the end. \\ (Int 16)}

Training people with intellectual disabilities is another support action highlighted by the interviewees. The main common element of training is related to personal economy management, and this is one of the areas in which providing support is more difficult due to

${ }^{1}$ The following acronyms are used to cite instruments: FG for the focus groups, Int for the interviews. 
the diversity of situations individuals find themselves in and the importance of this issue in relation to personal independence:

That's really complicated because they have to know how much they receive, all their expenses, if they are alone they have to sort out insurance... rent, electricity, gas, water, one bill comes every two months, another every month... it's about organizing their budget on a monthly basis, not just managing pocket money...

(Int 13)

Some participants mentioned other areas in which they implemented training actions: social skills, training related to rights, decisionmaking and knowledge of the community resources. Curiously, this last area is hardly mentioned as one that requires training.

Concerning the second theme (professional skills), the interviewees repeatedly referred to the transformation of the support model and the need to focus support on people's needs. The personalized support model is very recent in the context where the research was conducted and its implementation is still slow and gradual. As front-line managers, the participating professionals manage the distribution of support services and recognize the challenges involved in developing means of personalized support in the community. They referred extensively to some factors that make it difficult for them to exercise their professional role according to the social model. Firstly, professionals' actions are often determined by the nature of the institution they represent and work for (the service's model and culture, traits that define the organization, ways of operating, etc.). And related to this idea, in order to preserve their own authority, professionals sometimes display certain inconsistencies between what they say about rights and what they actually do in practice:

I think we professionals speak on the basis of the experience we have and especially the institution we represent. I mean, in this case we transmit missions, principles, values, the portfolio of services we offer... (...) We tend to provide care and give responses to clients, the person, the family, or whoever our client is, that preserve our authority. I mean, we make great speeches about the rights of people, but then the support we provide is more overprotective and preventive than we say. (Int 12)

Secondly, there were mentions of stereotypes and prejudices that have been accepted as a community (by services, professionals and families) and that, despite the theoretical discourse and ideological progress, are deeply rooted in their ways of thinking and acting. Among interviewees, a clear conviction is still lacking regarding independent living processes for people with disabilities, as some of them admit:

Our society has these prejudices, stigmas, stereotypes, which we as professionals also have, and we have assimilated them and are not aware of it... Basically deep down we professionals and the families are conservative, protectionist, we don't have much belief in the possibilities of people.

(Int 7)

They hardly defined any of the interpersonal skills linked to the interaction with the people with intellectual disabilities. Only two of the professionals interviewed mentioned the need to establish a relationship of trust, and that it is necessary to devote enough time to talk to users and get to know them well, and above all listen to them.

As for the third theme (Proposals for making advances in transforming the support model), the front-line managers fully recognized the need to make progress with incorporation of the social model, awarding people with disabilities a real central role. They also acknowledged that, when it comes to actions by professionals, more progress is needed to incorporate approaches focused on the individual. Consequently, they also emphasized the need to promote the decision-making processes of people with disabilities and offer them a variety and richness of experiences. Some actions highlighted by the professionals in this regard were empowering people with disabilities to take decisions, giving them the right support so they really understand that they can make decisions, and generating different experiences around them in order to help them decide which ones they like. Support decision-making of people with intellectual disabilities poses a challenge for professionals:

I think that when you allow space for the person to choose what they want, you are allowing space for things to happen that may not be what you want. And professionals do not like this. And so professionals may tend to manipulate, guide the answer to their own interest as a professional and not let the opinion of the individual prevail.

(Int 11)

In this sense, ongoing and updated training on the social model for people with disabilities and its implications with regard to support for both the front-line managers and other staff was a necessary action that was highly valued.

if we don't, there is a huge gap between current trends and what we as organizations and professionals know...

(Int 10)

Valuing and promoting natural means of support that play a predominant role in real social inclusion was also recommended:

...if they are all in the right community surroundings, they all have natural supports and we need to identify and use them. I think we should value these natural supports. If we don't, we can't make a personalized care plan. (Int2)

\section{2 | Self-advocates}

With regard to the first theme (actions associated with effective support), the self-advocates had a positive view of the information 
professionals provided them with to analyse possibilities for emancipation together with their families:

The professionals are the ones that help us and who help the family to understand things, what we can do, where we can go...

(FG4)

Training is also a support action highlighted by self-advocates. They especially valued the support received in managing their household budget, shopping, cooking, going to the doctor's and receiving guidance on all matters related to "paperwork":

We can do our accounts thanks to them, because otherwise... there are lots of expenses, and a lot of papers, and many things you don't understand, such as papers you don't understand.

(FG10)

Emotional support was the professional support action emphasized by a majority of the self-advocates across all of the focus groups. It was positively valued that the support professional is there to provide emotional support, which leads to them having a close relationship, often compared to a family member or close friend:

They (the professionals) are always there to help. Also with your mood, they're there saying "Is anything wrong?" They're there to make sure we feel alright and calm.

When she sees I'm sad, she talks to me and calms me down. Sometimes she gives me advice. I see her as a sister, another member of the family.

(FG4)

Across all focus groups, the professionals' skills most highly valued by self-advocates were interpersonal skills: feeling listened to and understood, feeling that they are receiving the time they need. They want support staff to show patience, inspire them with confidence and offer them unconditional support; this also means respecting the pace they go at and their needs:

That they understand what we're like. If you ever find you're not okay, you don't want to do anything, they don't insist, they don't keep on at you...

- That they have a lot of patience..

- And they're calm

- That they listen to you, help you, and understand your problems

- And trust... when you've been with them for many years, it feels like they're part of the family... (FG10).

Despite advances in the social model approach, authoritative styles are still very common among professionals. In this respect, some of the people with disabilities called for a gradual transformation in the style adopted by professionals from authoritarian to closer and more respectful of the needs and interests of people with disabilities.

There are some that act like a sergeant major. And there are others who use the new model. What does it mean? That some are like friends, except they are working. But they listen to you, they tell you things about themselves... There are many people, more and more now using the new model. But there are still some using the old one.

(Participant in FG2)

Regarding suggestions for transforming the support model (3rd theme), the self-advocates highlighted the need to be granted a more central role in the process leading to independent living. They proposed a more prominent role for the people with disability in providing support for other people's emancipation process, explaining and sharing their own experience of independent living:

I think it would be good if occasionally a group of people who have lived independently went to give talks... because we are the only ones who can truly explain what it's like to live like that.

(FG1)

Participants in focus groups suggested they needed to have a central role in taking decisions about themselves, but with support from professionals when needed.

I think each individual can decide what they need to do, but when you need help, they should give it to you. And you can decide what you do and don't want to do. That they help you make decisions, but value your opinion more.

The self-advocates also stated that they sometimes felt they did not receive enough support, and related this to a lack of staff. For this reason, some focus groups called for more support staff to be made available to them:

I'd like there to be two support people. Because when one is on holiday, the other could come. Or they could do it in shifts. For example, next week, my home support person is on holiday and can't accompany me to the psychiatrist, and I would have liked him to, because I'm starting a new treatment, and I don't know what's going to happen.

(FG6)

In relation to this, one element that cannot be overlooked is the need for greater job stability for support professionals that allows them to continue supporting people with disabilities. 
- For there to be more professionals in the flats.

- They work too many hours and maybe get too tired.

- There are people who volunteer now, but instead of volunteers, they should be given jobs or be paid...

- There should be more professionals. By the time you've got used to them, they have already left... (Participants in FG2).

\section{4 | DISCUSSION}

In this study, self-advocates and front-line managers gave their opinions regarding the support actions provided by professionals, skills of support staff, and proposals for improvement linked to the professional role. The analysis carried out allows us to assess common points and differences in priorities between professionals and self-advocates, which will contribute to a greater understanding of the main challenges that must be overcome in order to advance in independent living for people with intellectual disabilities.

With regard to support actions, both front-line managers and self-advocates acknowledged the importance of support actions aimed at both people with intellectual disabilities and their families in the emancipation process. Both positively valued training, coinciding in highlighting the importance of support for managing the household budget. Self-advocates also valued help with learning about domestic activities (shopping, cooking) and monitoring their health. Surprisingly, the need to implement support actions aimed at improving social networks and social inclusion in the community was mentioned by only four of the front-line managers. This little importance awarded to the community as a scenario for professional intervention coincides with the findings of previous studies that have explored the opinions of professionals (Clement \& Bigby, 2012; McConkey \& Collins, 2010).

As with other studies that have explored the perceptions of people with disabilities regarding professionals who provide support for independent living (Clarkson et al., 2009; Roeden et al., 2011), in all focus groups in the present research self-advocates most highly valued the emotional support received from support staff. Consequently, when discussing professional skills in focus groups, the self-advocates highly appreciated interpersonal skills such as patience, listening ability, respect, availability and accessibility, etc. In contrast, although the front-line managers emphasized the need to offer personalized support, they hardly mentioned the importance of establishing a trusting relationship with users, nor having a strong command of the skills inherent in this support. This imbalance between users' and practitioners' opinions regarding interpersonal skills fully coincides with the findings of previous studies (Dodevska \& Vassos, 2013; Hatton et al., 2009) and reinforces the need to take into account interpersonal skills in both the training and the recruitment of professionals.

The front-line managers and self-advocates both called for a more central role for people with intellectual disabilities in the support process. As found in the study by García Iriarte, Stockdale et al. (2016), the professionals stated that much progress is needed to incorporate the social model in both managing support and professional practice. In this sense, some of them acknowledged that the institution itself is sometimes an obstacle that makes it difficult for them to transform their support due to the difficulty of abandoning the care-based view that has permeated the services culture for decades. This concern is also consistent with contributions by Clement and Bigby (2010), Duggan and Linehan (2013), and McConkey and Collins (2010), which reflect the tensions existing between professionals and organizations due to difficulties in transforming the institutional culture.

The context where the research was carried out is undergoing a slow transition from the institutional model to a personalized support model, which is why some of the participants' comments focused on suggesting improvement proposals that would lead to progress in incorporating the personalized support model. Both self-advocates and front-line managers emphasized the need for individuals to take a prominent role in the process leading to their independent life and their empowerment in decision-making. One axis of the proposals for improvement is the training of professionals, suggested by the professionals themselves, which, as in the study by McConkey \& Collins, 2010; should be addressed not only to those involved directly in care but also those responsible for the management and distribution of support. Previous studies (Beadle-Brown, Bigby, \& Bould, 2015; Clement \& Bigby, 2012) have argued that the professionals in charge of organizations providing support for people with intellectual disabilities should have expertise and proven knowledge of the type of support they aim to provide. Firstly, according to the professionals' assessments of the difficulties involved in incorporating personcentred approaches, this should include comprehensive training in the social model and its implications for individualized support. On the other hand, in accordance with the opinions of self-advocates on the most valued professional skills, it is proposed that training in interpersonal skills be prioritized (as also suggested by Dodevska \& Vassos, 2013), as these come into play in personalized support processes. Secondly, in order to offer the emotional support so highly valued by self-advocates, it is necessary to take into account emotional training strategies for staff, which would allow them to reflect on the emotions evoked in the work they do and discuss the challenges inherent in this. This would require the construction of educational relationships that respect the needs and demands of individuals (in line with that suggested by Salmon, Holmes, \& Dodd, 2013). In this research, the participants did not consider a need for intervention or training in the implementation of support actions aimed at strengthening people's natural network. As pointed out by Verdugo et al. (2009), the emphasis is still on residential rather than community-based support in Spain, and this could be the reason why there is still no widespread awareness among professionals regarding their role in expanding the individual's natural support network. However, in order to make progress in the social inclusion of people offered support, and in accordance with the suggestions made by Bigby and Wiesel (2011), García Iriarte, Stockdale et al. (2016), 
and Power (2013), we propose that training actions aimed at professionals should strengthen those skills that allow them to analyse local contexts, identify sources of support and establish strategies that will enable people with disabilities to expand and maintain their natural networks in inclusive contexts. This involves prioritizing the community as a scenario where they perform a large part of their professional functions, beyond the context of the service itself or the home where the person lives.

Finally, the precarious working conditions of support staff who work in this sphere mentioned by front-line managers and selfadvocates (low salaries, difficult schedules, very limited time to give direct support to the individual) coincide with the observations of Hatton et al. (2009), Hawkins, Redley, and Holland (2011), and Hastings (2010) regarding support professionals in other contexts, which leads to resignations and therefore irregularity in the support offered. In Spain, access to personalized means of support is restricted to those who need little support, making independent living the privilege of a few rather than a right. Making progress in the incorporation of personalized approaches and the right to independent living as proposed by the CRPD (UN, 2006) entails the need for social policies to establish actions that allow all those who wish it to have access to personalized means of support that help them in their process towards emancipation and independent living, as well as a firm belief that support staff must be sufficiently trained and receive the right recognition at the professional level.

\section{1 | Limitations}

Kaehne and O'Connell (2010) and Kroll, Barbour, and Harris (2007) pointed out some advantages and difficulties of conducting focus groups with people with intellectual disabilities. Concerning the former, they provide a relaxed and informal environment in which people can explore issues through discussion and debate, information can be collected not only from each individual participant but also through interactions between participants, complex information can be collected from several people at the same time, and participants can enjoy sharing their beliefs and observations in a group of individuals with similar characteristics which, in turn, can derive in empowerment from the shared experience, as well as providing a forum for mutual support. In this sense, selfadvocates' participation in this research on independent living undoubtedly allowed an extensive discussion of the issues addressed in the focus groups.

Nevertheless, focus groups with people with intellectual disabilities can also be challenging. Group discussions can sometimes mask the individual voices of participants. The participation, in five of the groups, of the person who usually provides support to the self-advocacy group facilitated the involvement of all those who wished to participate, but their presence in the focus group may also have conditioned their interventions, since hardly any criticisms of professionals' actions were observed. However, it is difficult to estimate the extent to which the presence of this professional may have influenced the group discussion because a lack of criticism was a general tendency across all of the focus groups. It must be also taken into account that the groups participating in this research where pre-existing groups, whose members had sufficient communication skills and autonomy to be engaged regularly in discussions regarding their rights. Thus, as happens in most current research, the lack of representation of people with high levels of support makes it difficult to elicit the views of the learning disability community as a whole (Kaehne \& O'Connell, 2010). Assuming that the research conducted is not able to reflect the perspectives of those people with the greatest need for support, it is worth noting that a research issue like independent living needs to focus on the views of people who are currently experiencing it and, in the context where the research was developed, these are people with less support needs.

\section{ACKNOWLEDGMENTS}

We would like to express our gratitude to all those who agreed to participate in the discussion groups and interviews in order to share their experiences in this study, and especially to Beatriz Jiménez, who transcribed the interviews.

\section{ORCID}

Maria Pallisera (iD http://orcid.org/0000-0002-3703-4015

Judit Fullana (iD http://orcid.org/0000-0003-4356-4482

Gemma Díaz-Garolera (iD http://orcid.org/0000-0001-7437-2155

Carolina Puyalto (iD http://orcid.org/0000-0002-8313-0462

\section{REFERENCES}

Act 1/2013 on the Rights and Social Inclusion of people with disabilities (Madrid, BOE -Official State Bulletin, 3rd of December 2013)

Act 13/1982 on the Social Integration of people with disabilities (Madrid, BOE -Official State Bulletin, April 1982).

Barnes, C., \& Mercer, G. (2010). Exploring disability (2nd ed.). Cambridge, UK: Polity Press.

Barr, O., McConkey, R., \& McConaghie, J. (2003). Views of people with learning difficulties about current and future accommodation: The use of focus groups to promote discussion. Disability \& Society, 18 577-597. https://doi.org/10.1080/0968759032000097834

Beadle-Brown, J., Bigby, C., \& Bould, E. (2015). Observing practice leadership in intellectual and developmental disability services. Journal of Intellectual Disability Research, 59, 1081-1093. https://doi. org/10.1111/jir.12208

Bigby, C., \& Wiesel, I. (2011). Encounter as a dimension of social inclusion for people with intellectual disability: Beyond and between community presence and participation. Journal of Intellectual \& Developmental Disability, 36, 263-267. https://doi.org/10.3109/136 68250.2011 .619166

Björnsdóttir, K., Stefánsdóttir, G. V., \& Stefánsdóttir, Á. (2015). 'It's my life': Autonomy and people with intellectual disabilities. Journal of Intellectual Disabilities, 19, 5-21. https://doi. org/10.1177/1744629514564691

Bowey, L., Mcglaughlin, A., \& Saul, C. (2005). Assessing the barriers to achieving genuine housing choice for adults with a learning disability: The views of family carers and professionals. British 
Journal of Social Work, 35, 139-148. https://doi.org/10.1093/ bjsw/bch167

Boyatzis, R. (1998). Transforming qualitative information: Thematic analysis and code development. Thousand Oaks, CA: Sage.

Braun, V., \& Clarke, V. (2006). Using thematic analysis in psychology. Qualitative Research in Psychology, 3, 77-101. https://doi.org/10.119 1/1478088706qp063oa

Clarkson, R., Murphy, G. H., Coldwell, J. B., \& Dawson, D. L. (2009). What characteristics do service users with intellectual disability value in direct support staff within residential forensic services? Journal of Intellectual \& Developmental Disability, 34, 283-289. https://doi. org/10.3109/13668250903285630

Clement, T., \& Bigby, C. (2010). Group homes for people with intellectual disabilities. J.Kinglsley, London.

Clement, T., \& Bigby, C. (2012). Competencies of front-line managers in supported accommodation: Issues for practice and future research. Journal of Intellectual \& Developmental Disability, 37, 131-140. https:// doi.org/10.3109/13668250.2012.681772

Dodevska, G. A., \& Vassos, M. V. (2013). What qualities are valued in residential direct care workers from the perspective of people with an intellectual disability and managers of accommodation services? Journal of Intellectual Disability Research, 57, 601-615. https://doi. org/10.1111/j.1365-2788.2012.01565.x

Duggan, C., \& Linehan, C. (2013). The role of "natural supports" in promoting independent living for people with disabilities: A review of existing literature. British Journal of Learning Disabilities, 41, 199-207. https://doi.org/10.1111/bld.12040

Fereday, J., \& Muir-Cochrane, E. (2006). Demonstrating rigor using thematic analysis: A hybrid approach of inductive and deductive coding and theme development. International Journal of Qualitative Methods, 5, 80-92. https://doi.org/10.1177/160940690600500107

García Iriarte, E., Stockdale, J., McConkey, R., \& Keogh, F. (2016). The role of support staff as people move from congregated settings to group homes and personalized arrangements in Ireland. Journal of Intellectual Disabilities, 20, 152-164. https://doi. org/10.1177/1744629516633966

Garcia-Iriarte, E., McConkey, R., \& Gilligan, R. (2016). Disability and Human Rights: Global perspectives. London, UK: Palgrave.

Hastings, R. P. (2010). Support staff working in intellectual disability services: The importance of relationships and positive experiences. Journal of Intellectual \& Developmental Disability, 35, 207-210. https:// doi.org/10.3109/13668250.2010.492710

Hatton, C., Wigham, S., \& Craig, J. (2009). Developing measures of job performance for support staff in housing services for people with intellectual disabilities. Journal of Applied Research in Intellectual Disabilities, 22, 54-64. https://doi.org/10.1111/j.1468-3148.2008.00439.x

Hawkins, R., Redley, M., \& Holland, A. J. (2011). Duty of care and autonomy: How support workers managed the tension between protecting service users from risk and promoting their independence in a specialist group home. Journal of Intellectual Disability Research, 55, 873-884. https://doi.org/10.1111/j.1365-2788.2011.01445.x

Kaehne, A., \& O'Connell, C. (2010). Focus groups with people with learning disabilities. Journal of Intellectual Disabilities, 14, 133-145. https:// doi.org/10.1177/1744629510381939
Kroll, T., Barbour, R., \& Harris, J. (2007). Using focus groups in disability research. Qualitatitve Health Research, 17, 690-698. https://doi. org/10.1177/1049732307301488

Mansell, J., Beadle-Brown, J., \& with members of the Special Interest Research Group on Comparative Policy and Practice (2010). Deinstitutionalisation and community living: Position statement of the comparative policy and practice special interest research group of the international association for the scientific study of intellectual disabilities. Journal of Intellectual Disability Research, 54, 104-112. https://doi.org/10.1111/j.1365-2788.2009.01239.x

McConkey, R., \& Collins, S. (2010). The role of support staff in promoting the social inclusion of persons with an intellectual disability. Journal of Intellectual Disability Research, 54, 691-700. https://doi. $\operatorname{org} / 10.1111 /$ j.1365-2788.2010.01295.x

McConkey, R., Keogh, F., Bunting, B., García Iriarte, E., \& Watson, S. F. (2016). Relocating people with intellectual disability to new accommodation and support settings: Contrasts between personalized arrangements and group home placements. Journal of Intellectual Disabilities, 20, 109-120. https://doi.org/10.1177/1744629515624639

McGlaughlin, A., Gorfin, L., \& Saul, C. (2004). Enabling adults with learning disabilities to articulate their housing needs. British Journal of Social Work, 34, 709-726. https://doi.org/10.1093/bjsw/bch086

Power, A. (2013). Making space for belonging: critical reflections on the implementation of personalised adult social care under the veil of meaningful inclusion. Social Science and Medicine, 88, 68-75. https:// doi.org/10.1016/j.socscimed.2013.04.008

Roeden, J. M., Maaskant, M. A., \& Curfs, L. M. G. (2011). The views of clients with mild intellectual disabilities regarding their working relationships with caregivers. Journal of Applied Research in Intellectual Disabilities, 24, 398-406. https://doi.org/10.1111/j.1468-3148.2010.00622.x

Salmon, R., Holmes, N., \& Dodd, K. (2013). Reflections on change: Supporting people with learning disabilities in residential services. British Journal of Learning Disabilities, 42, 141-152.

United Nations (2006). Convention on the Rights of Persons with Disabilities. Retrieved from http://www.un.org/disabilities/documents/convention/convoptprot-s.pdf (accessed 29 January 2017).

Verdugo, M. A., Jenaro, C., \& Campo, M. (2009). ANED country report on the implementation of policies supporting independent living for disabled people. Retrieved from http://www.disability-europe.net/ downloads/273-aned-independent-living-report-spain (accessed 29 August 2017).

Wahlström, L., Bergström, H., \& Marttila, A. (2014). Promoting health of people with intellectual disabilities: Views of professionals working in group homes. Journal of Intellectual Disabilities, 18, 113-128. https://doi.org/10.1177/1744629514525133

How to cite this article: Pallisera M, Vilà M, Fullana J, Díaz-Garolera G, Puyalto C, Valls M-J. The role of professionals in promoting independent living: Perspectives of self-advocates and front-line managers. J Appl Res Intellect Disabil. 2018;00:1-10. https://doi.org/10.1111/jar.12470 


\section{APPENDIX 1}

Questions asked to professionals and self-advocates in interviews and focus groups regarding the role of professionals in promoting independent living.

Interviews with professionals

\begin{tabular}{ll} 
Topic & Guiding questions \\
\hline Role of professionals & Who are the professionals involved? \\
- How would you define the role of professionals in supporting people with disabilities to enhance & the development of their IL? What do you think are your main competencies? \\
- What training actions are developed (addressed to people with intellectual disabilities and/or their & families)? What skills are you working on with people with disabilities? \\
- Do you believe anything should be changed in the training offered to people with intellectual & disabilities throughout their educational process in order to enhance their IL?
\end{tabular}

Focus groups with self-advocates

\begin{tabular}{ll} 
Topic & Guiding questions \\
\hline Professionals & - What is the role of professionals in the IL process? \\
& - Strengths (things they do which help IL) \\
& - Things you believe should be improved (to promote IL) \\
Convention on the & - Difficulties and possibilities of implementing it. \\
Rights of Persons & - Things to improve, in relation to: economy, society, services and professionals, family. \\
with Disabilities, & \\
Article 19 on & \\
Independent Living &
\end{tabular}

